\title{
Pretreatment Serum Cystatin C Levels Predict Renal Function, but Not Tumor Characteristics, in Patients with Prostate Neoplasia
}

\author{
Feilong Yang, Dawei Li, Yu Di, Yongzhen Zhang, Yuanwei Zang, Juchao Ren, \\ Lei Yan, Zunlin Zhou, Hainan Liu, and Zhonghua Xu
}

Department of Urology, Qilu Hospital of Shandong University, Jinan 250012, China

Correspondence should be addressed to Dawei Li; lidaweimd@aliyun.com

Received 18 December 2016; Revised 10 March 2017; Accepted 20 June 2017; Published 24 July 2017

Academic Editor: Fabio Grizzi

Copyright (C) 2017 Feilong Yang et al. This is an open access article distributed under the Creative Commons Attribution License, which permits unrestricted use, distribution, and reproduction in any medium, provided the original work is properly cited.

\begin{abstract}
To evaluate the role of Cystatin C (Cys-C) in tumorigenesis and progression of prostate cancer (PCa), we retrospectively collected the clinical information from the records of 492 benign prostatic hyperplasia (BPH), 48 prostatic intraepithelial neoplasia (PIN), and 173 PCa patients, whose disease was newly diagnosed and histologically confirmed. Pretreatment serum Cys-C levels were compared across the various groups and then analyzed to identify relationships, if any, with clinical and pathological characteristics of the PCa patient group. There were no significant differences in serum Cys-C levels among the three groups $(P>0.05)$. In PCa patients with normal SCr levels, patient age was correlated with serum Cys-C level $(P \leq 0.001)$ but did not correlate with alkaline phosphatase (AKP), lactate dehydrogenase (LDH), prostate specific antigen (PSA), Gleason score, or bone metastasis status $(P>$ $0.05)$. Age and $\mathrm{SCr}$ contributed in part to the variations in serum Cys-C levels of PCa patients $(r=0.356, P \leq 0.001 ; r=0.520, P \leq$ 0.001). In conclusion, serum Cys-C levels predict renal function in patients with prostate neoplasia, but were not a biomarker for the development of prostate neoplasia, and were not correlated with the clinicopathological characteristics of PCa.
\end{abstract}

\section{Introduction}

Prostate cancer (PCa) develops in the unique gland of the male reproductive system, where it becomes a detriment to men's health. In 2015, PCa was ranked the second most frequently diagnosed cancer in males worldwide and the fifth leading cause of cancer deaths in the world [1]. In the United States, it was estimated that 241,740 new cases developed in 2012, making it the most frequently diagnosed cancer type therein [2]. In addition, 28,170 deaths were attributed to PCa, accounting for more than ten percent of cancer deaths in men [2]. The incidence of PCa varies widely worldwide. PCa is least common in South and East Asia and most common in United States, with moderate incidences in Europe. Moreover, in China, it was estimated that the incidence of prostate cancer was ranked sixth and the mortality of prostate cancer was ranked seventh in men [3]. Though widely studied, the precise mechanism of prostate cancer has not yet been fully clarified and further investigation is needed.
Cystatin C (Cys-C), encoded by the CST3 gene, belongs to the type two cystatin superfamily and has been extensively studied since it was first described in $1961[4,5]$. CST3 is located on the short arm of chromosome 20, spans $7.3 \mathrm{~kb}$ [6], contains four exons, encodes a 120 -amino acid active cysteine proteinase inhibitor [7], and shares several features with housekeeping genes [6]. Cys- $\mathrm{C}$ is ubiquitously expressed in nucleated cells $[8,9]$ in tissues such as the testis, epididymis, seminal vesicle, and prostate [10] and is then secreted into various human fluids to inhibit the activity of cysteine proteases such as papain and cathepsins $\mathrm{B}, \mathrm{H}, \mathrm{K}$, and L [11]. Moreover, Cys- $\mathrm{C}$ is considered to function as a p53-inducible tumor suppressor and apoptotic mediator that negatively regulates cathepsin $\mathrm{L}$ activity during carcinogenesis [9]. Therefore, Cys- $\mathrm{C}$ is believed to play a critical role in the tumor suppressive function of p53 [9], as well as in extracellular, protein homeostasis. An imbalance between Cys- $C$ and cysteine proteinases has been observed in the pathogenesis of a broad spectrum of diseases $[12,13]$, 
including cancer [14-17]. However, the diagnostic role of Cys$\mathrm{C}$ in cancers, such as renal cell carcinoma [18] and pancreatic tumors [18], has been dismissed. Recent studies by Wegiel et al. and Jiborn et al. indicated that Cys- $\mathrm{C}$ was downregulated in PCa specimens $[19,20]$. Cys- $C$ was also found to modulate the invasion of PCa cells by means of the androgen receptor and MAPK/Erk2 pathways [19]. Aberrant expression of Cys$\mathrm{C}$ is associated with neuroendocrine differentiation in $\mathrm{PCa}$ [20]. Studies from another group also revealed that serum Cys-C levels may distinguish PCa patients from BPH patients and functioned as an indicator for the treatment of metastatic PCa with zoledronic acid in a small patient group [15, 21]. Taken together, published studies have reported both positive $[15,21,22]$ and negative [23] effects of serum Cys-C levels on predicting malignancies. Thus, the feasibility of using serum Cys-C levels in cancer detection remains controversial.

We evaluated the diagnostic significance of circulating Cys-C levels in patients with prostate neoplasia, including $\mathrm{BPH}, \mathrm{PIN}$, and PCa. We also explored the relationship between serum Cys- $\mathrm{C}$ levels and clinicopathological characteristics of PCa patients.

\section{Materials and Methods}

2.1. Patient Population. The study was reviewed and approved by the Ethics Committee at Qilu Hospital of Shandong University and the Approval Number is KYLL-2015(KS)-156. We retrospectively collected clinical and pathological information from the records of inpatients that were newly diagnosed with prostate neoplasia and treated at the Department of Urology, Qilu Hospital of Shandong University between February 2010 and September 2013. Histologic confirmation of $\mathrm{BPH}, \mathrm{PIN}$, or PCa was obtained for all patients. None of the patients received preoperative hormonal therapy or radiotherapy. Patients with clinical characteristics such as (a) coexistence of prostate neoplasia and malignancy of other tissues or organs, (b) histologically diagnosed PCa but not adenocarcinoma, or (c) inadequate clinical information were excluded.

2.2. Sample Test and Data Collection. After an overnight fast, $5 \mathrm{~mL}$ of venous blood was obtained from patients with prostate neoplasia and assayed immediately before clinical treatment. Blood samples were deposited into test tubes containing a clot activator and gel, allowed to clot at room temperature, and subsequently centrifuged at $2000 \mathrm{rpm}$ for $10 \mathrm{~min}$. Serum was then collected to determine the concentration of Cys-C and other biochemical markers. The circulating Cys-C levels were tested with immunoturbidimetric method using a Roche Cobas 8000 analyzer with reagents purchased from BioSino Bio-Technology \& Science Inc., Beijing, China. The levels of SCr, AKP, and LDH were determined using a Roche Cobas 8000 analyzer with reagents purchased from Roche. PSA was quantified using a Roche Cobas 601 analyzer, also with Roche reagents. The tests were completed according to the manufacturers' instructions. Clinical data, including age, SCr, Cys-C, PSA, AKP, LDH, Gleason score, and ECT (Bone Imaging), were retrieved from patient files. We first compared pretreatment serum Cys- $\mathrm{C}$ levels among all patients in the three groups. Subsequently, subclass analyses were conducted to exclude the possible effects of renal function on the pretreatment levels of Cys-C. Furthermore, we performed statistical analyses to compare the $\mathrm{BPH}$ and PIN groups. We also analyzed the association of serum Cys-C levels with clinical characteristics of $\mathrm{PCa}$ patients. Linear correlations among age, $\mathrm{SCr}$, and $\mathrm{Cys}-\mathrm{C}$ were also evaluated.

2.3. Statistical Analysis. The normal distribution of quantitative data in the various groups was assessed by the Kolmogorov-Smirnov test. Normally distributed data were expressed as the mean \pm standard deviation (SD), while the median (range) was reported for data not following a Gaussian distribution. Statistical analyses were accordingly performed using the parametric Student's $t$-test, one-way ANOVA, or the nonparametric Mann-Whitney $U$ test and Kruskal-Wallis $H$ test. Qualitative data were reported as numbers and percentages, and the Pearson $\chi^{2}$ test was used to compare differences among various groups. Pearson correlation coefficients were calculated to examine the associations among age, SCr, and Cys-C. Data were analyzed and processed using the Statistical Package for Social Sciences version 16.0 (SPSS 16.0, SPSS Inc., Chicago, IL, USA). All probabilities $(P)$ were two-tailed and $P$ values less than 0.05 were considered statistically significant.

\section{Results}

3.1. Characteristics of Study Population. The study group consisted of patients with prostate neoplasia consecutively presenting at the Department of Urology, Qilu Hospital of Shandong University. In total, 492 BPH, 48 PIN, and 173 PCa patients conforming to inclusive criteria were eligible for inclusion in the final study. The ages of eligible BPH, PIN, and PCa patients were $70.50 \pm 7.55,70.35 \pm 7.95$, and $70.88 \pm 8.01$ years, respectively $(P=0.775)$. All patients were further grouped according to their levels of $\operatorname{SCr}(P=0.916)$. Clinical characteristics of enrolled patients are presented in Table 1.

3.2. Serum Cys-C Levels in Patients with Prostate Neoplasia. The levels of serum Cys-C were 1.04 (0.59-4.02), 1.02 (0.59-2.43), and $1.03(0.59-3.08) \mathrm{mg} / \mathrm{L}$ in the BPH, PIN, and PCa groups, respectively $(P=0.765)$ (Figure $1(\mathrm{a}))$. Patients were then further grouped and analyzed according to their levels of SCr (less or greater than $115 \mu \mathrm{mol} / \mathrm{L})(P=$ 0.916) (Table 1). There were insignificant associations with serum Cys-C levels among patients with SCr levels less than $115 \mu \mathrm{mol} / \mathrm{L}(P=0.769)$ (Figure $1(\mathrm{~b})$ ) or greater than $115 \mu \mathrm{mol} / \mathrm{L}(P=0.609)$ (Figure $1(\mathrm{c}))$. Levels of serum Cys$\mathrm{C}$ were higher in $\mathrm{BPH}(P<0.001)$ and $\mathrm{PCa}(P \leq 0.001)$ patients with SCr levels greater than $115 \mu \mathrm{mol} / \mathrm{L}$ (Figures $1(\mathrm{~d}$ ) and 1(e)) than those in the PIN group. Moreover, the levels of serum Cys-C in PIN patients with SCr levels greater than $115 \mu \mathrm{mol} / \mathrm{L}$ were similar to those in patients with SCr levels less than $115 \mu \mathrm{mol} / \mathrm{L}(P=0.126)$ (Figure $1(\mathrm{f}))$.

3.3. Association of Serum Cys-C Levels with Clinical Characteristics of PCa. Considering the effect of SCr on levels of serum 
TABLE 1: Clinical characteristics of patients with prostate neoplasia.

\begin{tabular}{|c|c|c|c|c|}
\hline Characteristics & $\mathrm{BPH}$ & PIN & $\mathrm{PCa}$ & $P$ value \\
\hline Patients $(n)$ & 492 & 48 & 173 & \\
\hline Age (y) & $70.50 \pm 7.55$ & $70.35 \pm 7.95$ & $70.88 \pm 8.01$ & $0.775^{\mathrm{a}}$ \\
\hline Cys-C (mg/L) & $1.04(0.59-4.02)$ & $1.02(0.59-2.43)$ & $1.03(0.59-3.08)$ & $0.765^{\mathrm{b}}$ \\
\hline \multicolumn{5}{|l|}{$\operatorname{SCr}(n, \%)$} \\
\hline$\leq 115 \mu \mathrm{mol} / \mathrm{L}$ & $455(92.5)$ & $44(91.7)$ & $159(91.9)$ & $0.916^{\mathrm{c}}$ \\
\hline$>115 \mu \mathrm{mol} / \mathrm{L}$ & $37(7.5)$ & $4(8.3)$ & $14(8.1)$ & \\
\hline
\end{tabular}

BPH: benign prostatic hyperplasia; PIN: prostate intraepithelial neoplasia; PCa: prostate cancer; Cys-C: cystatin C; SCr: serum creatinine; $P^{\mathrm{a}}$ : one-way ANOVA test; $P^{\mathrm{b}}$ : Kruskal-Wallis $H$ test; $P^{\mathrm{c}}$ : Pearson $\chi^{2}$ test.

TABLE 2: The level of serum Cys-C in PCa patients with normal SCr.

\begin{tabular}{|c|c|c|c|}
\hline Characteristics & $n(\%)$ & Mean \pm SD & $P$ value \\
\hline Patients (n) & $159(100)$ & $1.04 \pm 0.22$ & \\
\hline Age & & & $0.000^{\mathrm{a} *}$ \\
\hline$\leq 70 y$ & $73(45.91)$ & $0.96 \pm 0.17$ & \\
\hline$>70 y$ & $86(54.09)$ & $1.10 \pm 0.24$ & \\
\hline AKP & & & $0.133^{*}$ \\
\hline$>125 \mathrm{U} / \mathrm{L}$ & $20(12.58)$ & $0.97 \pm 0.21$ & \\
\hline$\leq 125 \mathrm{U} / \mathrm{L}$ & $139(87.42)$ & $1.05 \pm 0.22$ & \\
\hline $\mathrm{LDH}$ & & & $0.368^{*}$ \\
\hline$>230 \mathrm{U} / \mathrm{L}$ & $24(15.09)$ & $1.07 \pm 0.26$ & \\
\hline$\leq 230 \mathrm{U} / \mathrm{L}$ & $135(84.91)$ & $1.03 \pm 0.21$ & \\
\hline PSA & & & $0.471^{*}$ \\
\hline$>5 \mathrm{ng} / \mathrm{mL}$ & $147(92.45)$ & $1.04 \pm 0.21$ & \\
\hline$\leq 5 \mathrm{ng} / \mathrm{mL}$ & $12(7.55)$ & $0.99 \pm 0.30$ & \\
\hline Gleason score & & & $0.574^{\mathrm{b} *}$ \\
\hline$\leq 5$ & $4(2.52)$ & $1.03 \pm 0.21$ & \\
\hline 6 & $22(13.84)$ & & \\
\hline 7 & $65(40.88)$ & & \\
\hline 8 & $40(25.16)$ & $1.05 \pm 0.23$ & \\
\hline 9 & $21(13.21)$ & & \\
\hline 10 & $1(0.63)$ & & \\
\hline Missing information & $6(3.77)$ & - & \\
\hline ECT (bone metastasis) & & & $0.432^{\mathrm{c} *}$ \\
\hline Yes & $27(16.98)$ & $1.06 \pm 0.21$ & \\
\hline No & $55(34.59)$ & $1.02 \pm 0.12$ & \\
\hline Possible & $26(16.35)$ & - & \\
\hline Unknown & $51(32.08)$ & - & \\
\hline
\end{tabular}

SCr: serum creatinine; PCa: prostate cancer; Cys-C: cystatin C; $P^{\mathrm{a}}<0.05 ; P^{\mathrm{b}}$ : Gleason score $\leq 7$ versus Gleason score $>7 ; P^{\mathrm{c}}$ : bone metastasis versus nonbone metastasis; $P^{*}$ : Student's $t$-test.

Cys- $\mathrm{C}$, the associations between serum Cys-C levels and clinical characteristics of 159 PCa patients with normal SCr (less than $115 \mu \mathrm{mol} / \mathrm{L}$ ) were further evaluated. PCa patients were stratified accordingly, and these data are presented in Table 2. We found that the levels of serum Cys-C in older PCa patients (more than 70 years) were higher than in younger patients $(P \leq 0.001)$ (Figure $2(\mathrm{a})$ ). Moreover, there were insignificant associations between the levels of serum Cys- $C$ and clinical characteristics, such as AKP, LDH, PSA, Gleason score, and bone metastasis status (all $P>0.05$ ) (Figures $2(b)-2(f))$.
3.4. Levels of Serum Cys-C Correlate with SCr and Age in $\mathrm{PCa}$ Patients. Using linear correlation analyses, there were positive correlations between circulating Cys-C levels, age $(r=0.356, P \leq 0.001)$ (Figure 3(a)), and SCr $(r=0.167$, $P=0.036$ ) (Figure 3(b)) in PCa patients. In addition, the $\mathrm{SCr}$ levels of $\mathrm{PCa}$ patients correlated with their pretreatment levels of serum Cys-C $(r=0.520, P \leq 0.001)$ (Figure 3(c)).

\section{Discussion}

Cys-C is a cationic, nonglycosylated protein with a molecular mass of $13 \mathrm{kDa}$. It is ubiquitously expressed in all nucleated 


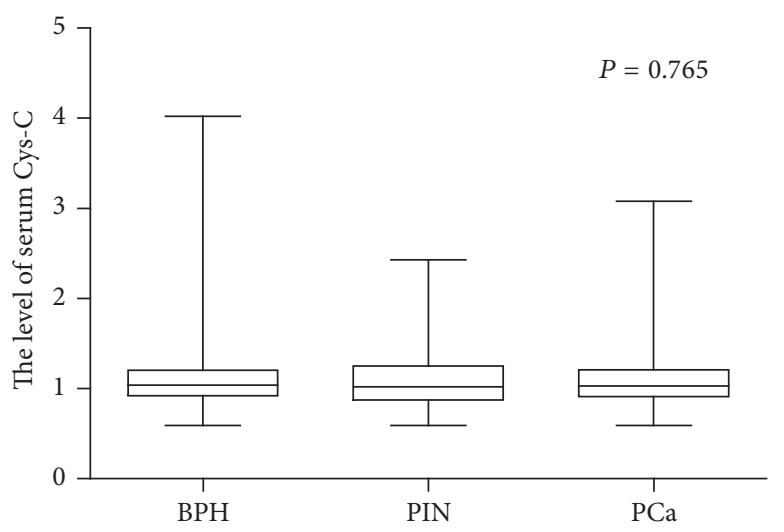

(a)

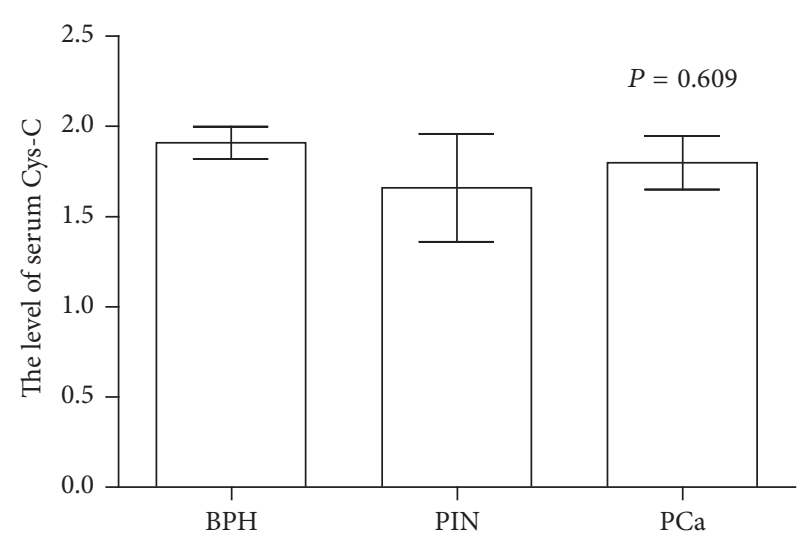

(c)

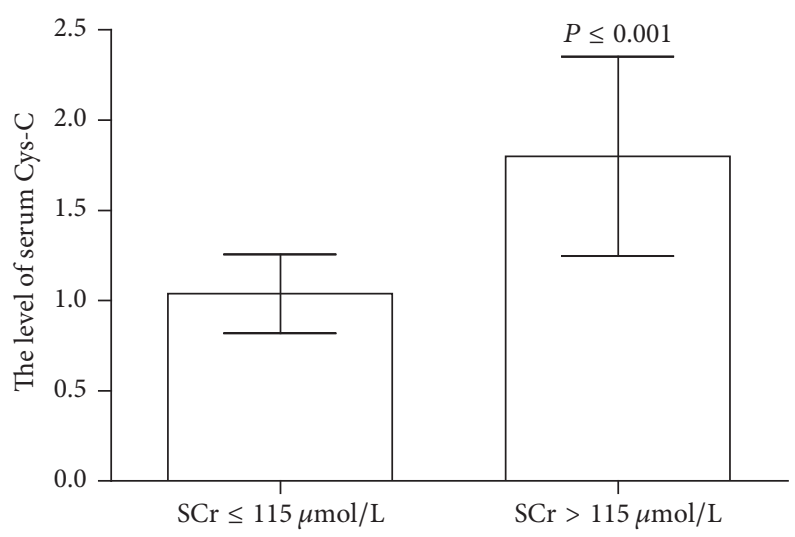

(e)

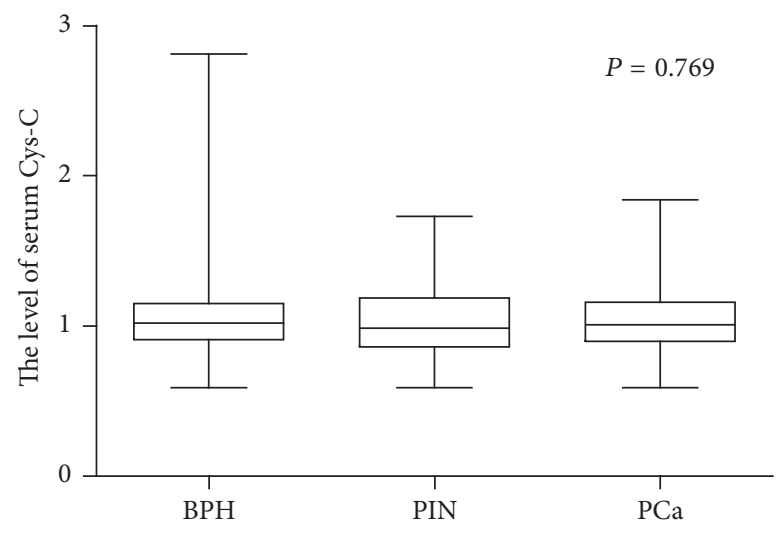

(b)

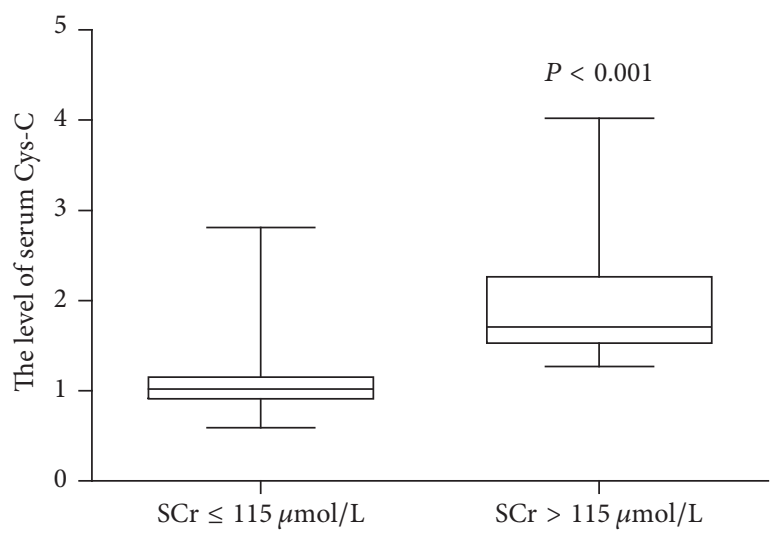

(d)

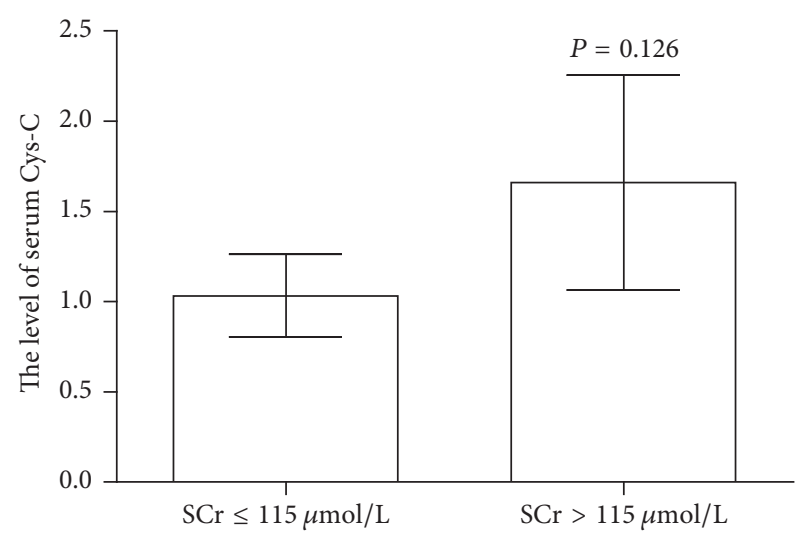

(f)

FIgURE 1: The comparisons of serum Cys-C in various groups of patients with prostate neoplasia. The comparison of serum Cys-C in total patients with prostate neoplasia $(P=0.765)(\mathrm{a})$; in patients with normal SCr $(P=0.769)(\mathrm{b})$; in patients with high $\mathrm{SCr}(P=0.609)(\mathrm{c})$; in BPH patients $(P<0.01)(\mathrm{d})$; in PCa patients $(P \leq 0.001)(\mathrm{e})$; in PIN patients $(P=0.126)(\mathrm{f})$. $P$ : parametric Student's $t$-test.

cells [8], widely distributed in human biological fluids [9], freely filtered through renal glomeruli, and uniquely and almost completely reabsorbed and catabolized in the proximal tubules [18]. Therefore, its classic role as a sensitive marker for renal function has been extensively studied [24-27] and further confirmed in a meta-analysis [28]. In addition to its role in predicting kidney function, Cys$\mathrm{C}$ is also a marker for inflammation [12], infection [13], tumorigenesis [16], prostate cancer pathological grade [20], malignant progression $[14,17]$, and several other processes $[29,30]$. In the present study, we collected and analyzed clinical information to evaluate the diagnostic significance of circulating Cys-C in patients with prostate neoplasia and explored the relationship between serum Cys- $\mathrm{C}$ levels and clinicopathological characteristics of PCa patients. To our knowledge, this study is one of the first studies to focus on alterations circulating Cys- $\mathrm{C}$ concentrations in patients with PIN. 


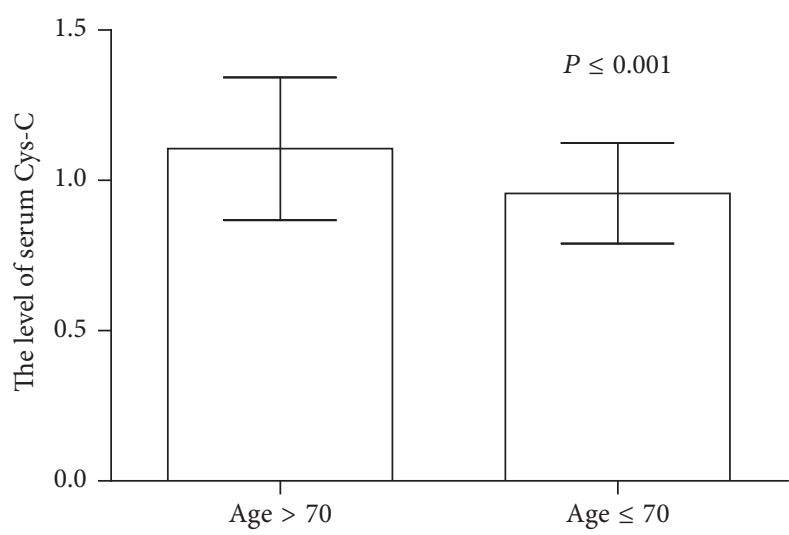

(a)

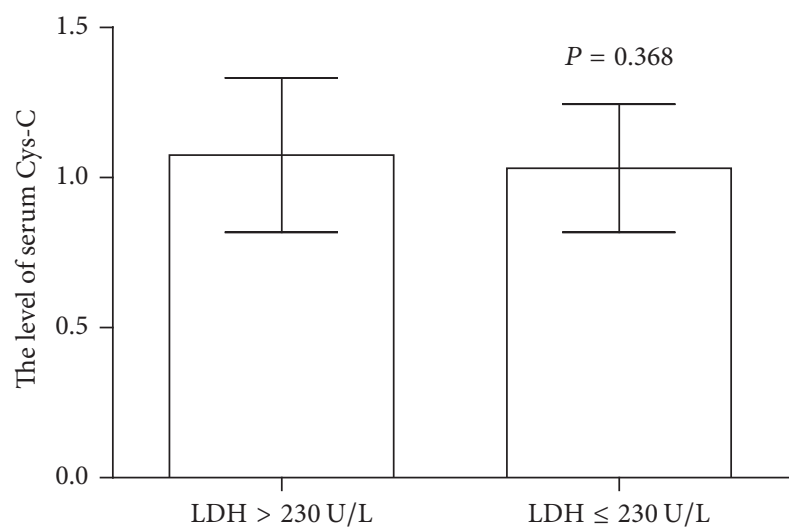

(c)

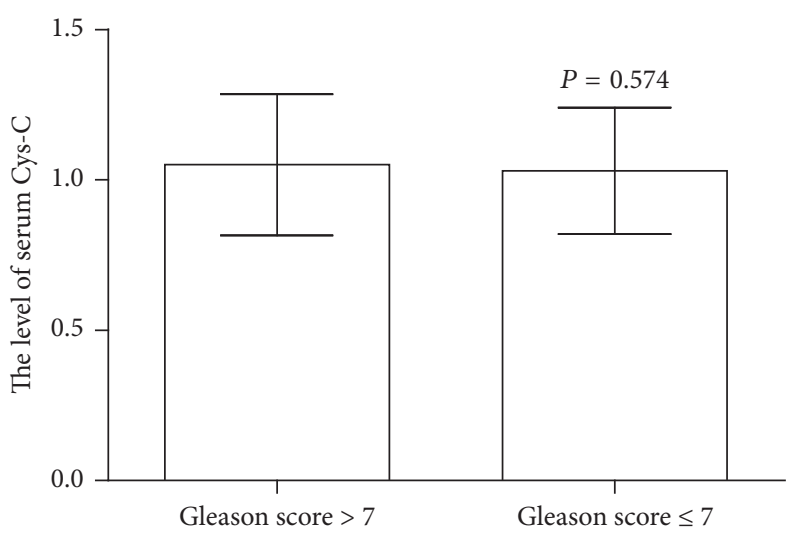

(e)

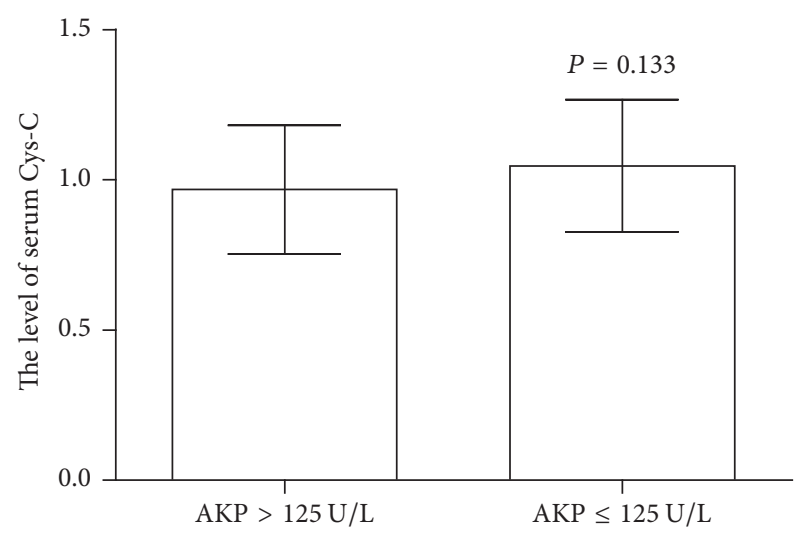

(b)

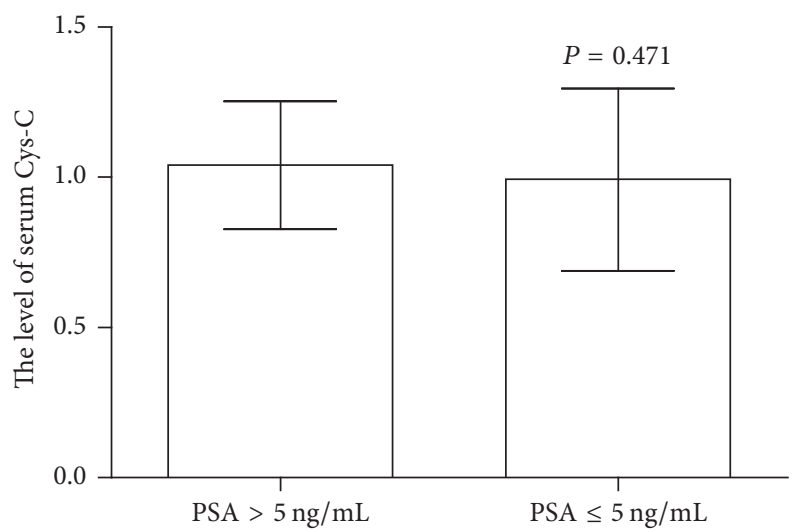

(d)

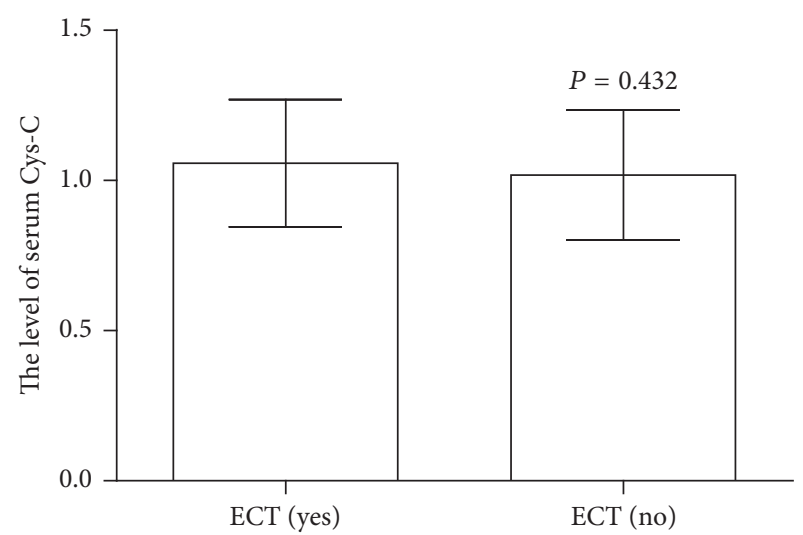

(f)

Figure 2: The comparisons of serum Cys-C in subgroup analyses of PCa patients with normal SCr. The subgroup comparison of serum Cys-C in patients with normal SCr based on patient age $(P \leq 0.001)$ (a); AKP $(P=0.133)(\mathrm{b})$; LDH $(P=0.368)(\mathrm{c})$; PSA $(P=0.471)$ (d); Gleason score $(P=0.574)(\mathrm{e})$; the status of bone metastasis $(P=0.432)(\mathrm{f}) . P$ : parametric Student's $t$-test.

In the present study, there were no significant differences in the levels of serum Cys-C among all patients in the three groups $(P=0.765)$. Our result was in accordance with that from another study focusing on ovarian cancer, which excluded the role of serum Cys-C level as possible biomarker [23]. To exclude the impact of renal function on Cys-C levels, all patients were further grouped based on their $\mathrm{SCr}$ levels. Again, no differences in the levels of serum Cys-C were detected among the three prostate neoplasia groups in either the high SCr $(P=0.609)$ or normal SCr $(P=$ 0.769 ) groups. However, a recent study found that the level of serum Cys-C could distinguish PCa from BPH patients [15]. The conflicting results between these two studies may be attributed to differences in the ages of the patient groups. In our study, patient age was normally distributed, and there were no significant differences among the three groups $(P=$ $0.775)$. However, in the study by Tumminello et al. [15], PCa patients ( $72.4 \pm 7.8$ years) were much older than $\mathrm{BPH}$ patients 


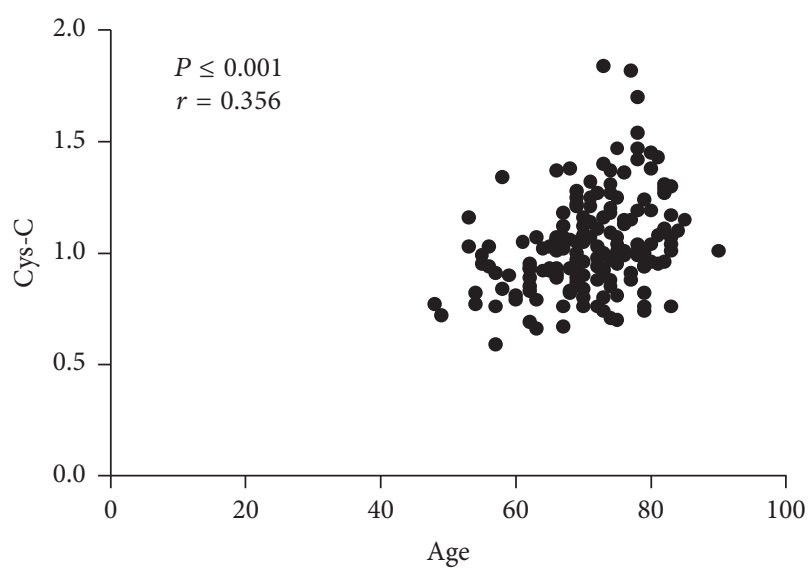

(a)

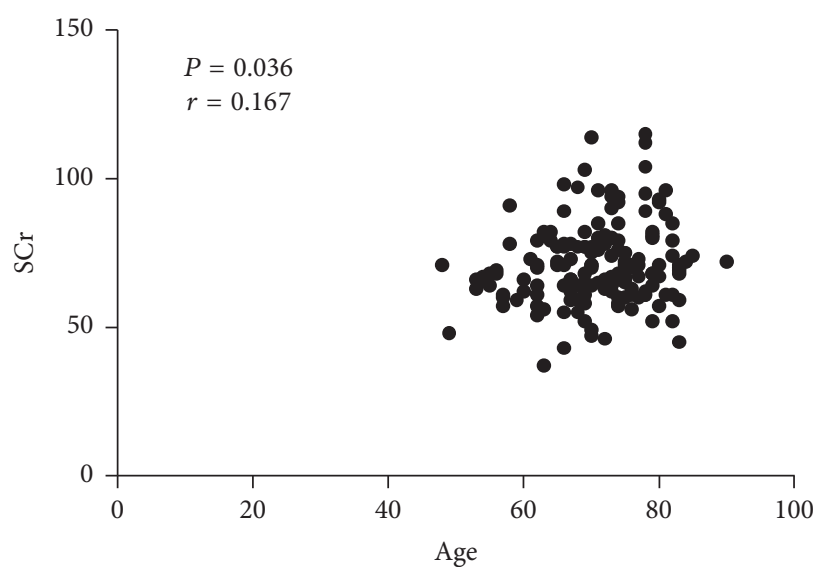

(b)

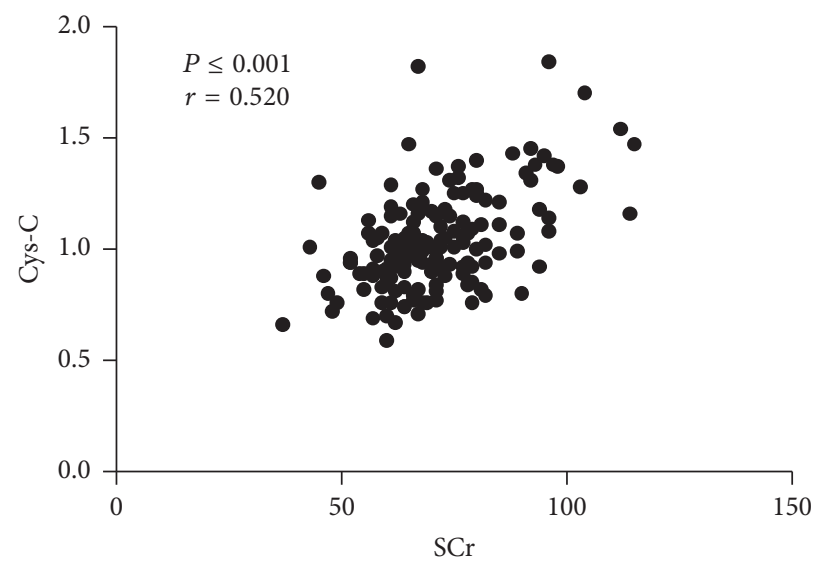

(c)

Figure 3: Correlations of serum Cys-C, SCr, and age in patients with PCa (normal SCr). Correlation of serum Cys-C and patient age $(r=$ $0.356, P \leq 0.001)(\mathrm{a})$; correlation of SCr and patient age $(r=0.167, P=0.036)(\mathrm{b})$; correlation of SCr and serum Cys-C $(r=0.520, P \leq 0.001)$ (c). $P$ : statistical significance; $r$ : correlation coefficient according to Pearson correlation test.

$(62.8 \pm 6.2$ years $)$. Age-related reductions in the glomerular filtration rate (GFR) [31,32] lead to age-dependent increases in the concentrations of serum Cys-C [16]. Still, SCr affected the levels of serum Cys-C in both the BPH $(P=0.001)$ and PCa $(P \leq 0.001)$ groups. However, SCr did not affect the level of serum Cys-C in the PIN group $(P=0.126)$. These results could be explained by the small number of PIN patients with SCr levels greater than $115 \mu \mathrm{mol} / \mathrm{L}(n=4)$. However, the mean serum Cys-C level in PIN patients with high SCr $(1.66 \pm 0.60 \mu \mathrm{mol} / \mathrm{L})$ was higher than that in PIN patients with normal SCr levels $(1.03 \pm 0.23 \mu \mathrm{mol} / \mathrm{L})$.

We next investigated the possible relationship between circulating Cys-C and clinicopathological parameters in $\mathrm{PCa}$ patients with normal SCr. Unfortunately, when PCa patients were stratified according to levels of AKP, LDH, PSA, bone metastasis status, and Gleason score, no significant differences in serum Cys-C levels were found among the various groups (all $P>0.05$ ). Our results were consistent with those of a previous study containing relatively few subjects [15]. However, we found that PCa patients older than seventy years of age had higher serum Cys- $C$ levels than their younger counterparts $(1.10 \pm 0.24$ versus $0.96 \pm 0.17 \mathrm{mg} / \mathrm{L}, P \leq 0.001)$.
As discussed above, older age may alter renal function as well as levels of serum Cys-C [33]. Next, the possible relationships among serum Cys-C, age, and $\mathrm{SCr}$ were tested using linear correlation analyses. As expected, serum Cys-C levels were positively correlated with patient age $(r=0.356, P \leq 0.001)$ and SCr $(r=0.520, P \leq 0.001)$. Moreover, we found that patient age was positively correlated with $\mathrm{SCr}(r=0.167$, $P=0.036)$.

Taken together, the value of serum Cys-C levels as a feasible predictor for PIN and PCa was limited for the following reasons. First, Cys- $\mathrm{C}$ is a housekeeping protein ubiquitously expressed in all nucleated cells and highly expressed in the male reproductive system. Unlike PSA, its expression was actually downregulated in prostate tumors and its circulating level may be affected by complex mechanisms. Second, prostate neoplasia was common in older males. Age-dependent reductions in GFR and declines in renal function would confound with changes in the levels of serum Cys-C [16]. Third, the male urethra traverses through the center of the prostate gland. Obstruction of the urethra caused by a prostate lesion may impair kidney function, which may impact levels of circulating Cys-C. 
In conclusion, no statistically significant differences in the levels of serum Cys-C were found among the BPH, PIN, and PCa groups. Circulating Cys-C was not a potential marker for prostate tumorigenesis and was not a reliable predictor for clinicopathological characteristics of PCa patients. The increases in serum Cys-C levels in the elderly PCa group may be partly ascribed to age-dependent reductions in GFR.

\section{Conflicts of Interest}

The authors declare that they have no conflicts of interest.

\section{Authors' Contributions}

Feilong Yang and Dawei Li contributed equally to the manuscript.

\section{Acknowledgments}

This study was supported by financial grants from the National Natural Science Foundation of China (Grant no. 81502213) (https://isisn.nsfc.gov.cn/egrantweb/), the Natural Science Foundation of Shandong Province (Grant nos. 2010ZRE27284 and ZR2015HM046) (http://jihlx.sdstc.gov .cn/STDPMS/ZR/Default.aspx), the Science and Technology Development Program of Shandong Province (26010104011178) (http://jihlx.sdstc.gov.cn/STDPMS/GG/Default.aspx), and the Focused Research and Development Program of Shandong Province (2016GSF201171) (http:// jihlx.sdstc.gov.cn/STDPMS/GG/Default.aspx).

\section{References}

[1] L. A. Torre, F. Bray, R. L. Siegel, J. Ferlay, and J. LortetTieulent, "Global cancer statistics, 2012," CA: A Cancer Journal for Clinicians, vol. 65, no. 2, pp. 87-108, 2015.

[2] R. Siegel, D. Naishadham, and A. Jemal, "Cancer statistics, 2012," CA: A Cancer Journal for Clinicians, vol. 62, no. 1, pp. 10-29, 2012.

[3] W. Chen, R. Zheng, P. D. Baade et al., "Cancer statistics in China, 2015," CA: Cancer Journal for Clinicians, vol. 66, no. 2, pp. 115132, 2016.

[4] E. A. Butler and F. V. Flynn, "The occurrence of post-gamma protein in urine: a new protein abnormality," Journal of Clinical Pathology, vol. 14, no. 2, pp. 172-178, 1961.

[5] C. F. Macpherson and J. B. Cosgrove, "Immunochemical evidence for a gamma globulin peculiar to cerebrospinal fluid," Canadian journal of biochemistry and physiology, vol. 39, pp. 1567-1574, 1961.

[6] M. Abrahamson, I. Olafsson, A. Palsdottir et al., "Structure and expression of the human cystatin C gene," Biochemical Journal, vol. 268, no. 2, pp. 287-294, 1990.

[7] M. Abrahamson, A. Grubb, I. Olafsson, and Å. Lundwall, "Molecular cloning and sequence analysis of cDNA coding for the precursor of the human cysteine proteinase inhibitor cystatin C," FEBS Letters, vol. 216, no. 2, pp. 229-233, 1987.

[8] M. A. Ferguson and S. S. Waikar, "Established and emerging markers of kidney function," Clinical Chemistry, vol. 58, no. 4, pp. 680-689, 2012.
[9] J. Mori, C. Tanikawa, Y. Funauchi, P. H. Y. Lo, Y. Nakamura, and K. Matsuda, "Cystatin C as a p53-inducible apoptotic mediator that regulates cathepsin L activity," Cancer Science, vol. 107, no. 3, pp. 298-306, 2016.

[10] T. Jiborn, M. Abrahamson, H. Wallin et al., "Cystatin C is highly expressed in the human male reproductive system," Journal of Andrology, vol. 25, no. 4, pp. 564-572, 2004.

[11] R. Janowski, M. Kozak, E. Jankowska et al., "Human cystatin $\mathrm{C}$, an amyloidogenic protein, dimerizes through threedimensional domain swapping," Nature Structural Biology, vol. 8, no. 4, pp. 316-320, 2001.

[12] R. Lertnawapan, A. Bian, Y. H. Rho et al., "Cystatin C is associated with inflammation but not atherosclerosis in systemic lupus erythematosus," Lupus, vol. 21, no. 3, pp. 279-287, 2012.

[13] Y.-T. Lee, S.-C. Chen, L.-Y. Shyu et al., "Significant elevation of plasma cathepsin B and cystatin $\mathrm{C}$ in patients with communityacquired pneumonia," Clinica Chimica Acta, vol. 413, no. 5-6, pp. 630-635, 2012.

[14] M. Dreilich, G. Wagenius, S. Bergström et al., "The role of cystatin $\mathrm{C}$ and the angiogenic cytokines VEGF and bFGF in patients with esophageal carcinoma," Medical Oncology, vol. 22, no. 1, pp. 29-38, 2005.

[15] F. M. Tumminello, G. Badalamenti, L. Incorvaia, F. Fulfaro, C. D'Amico, and G. Leto, "Serum interleukin-6 in patients with metastatic bone disease: Correlation with cystatin C," Medical Oncology, vol. 26, no. 1, pp. 10-15, 2009.

[16] G. Ohara, K. Miyazaki, K. Kurishima et al., "Serum levels of cystatin C in elderly lung cancer patients," Oncology Letters, vol. 3, no. 2, pp. 303-306, 2012.

[17] H. Nishikawa, Y. Ozaki, T. Nakanishi et al., "The role of cathepsin B and cystatin $\mathrm{C}$ in the mechanisms of invasion by ovarian cancer," Gynecologic Oncology, vol. 92, no. 3, pp. 881886, 2004.

[18] B. Jacobsson, H. Lignelid, and U. S. R. Bergerheim, “Transthyretin and cystatin $\mathrm{C}$ are catabolized in proximal tubular epithelial cells and the proteins are not useful as markers for renal cell carcinomas," Histopathology, vol. 26, no. 6, pp. 559-564, 1995.

[19] B. Wegiel, T. Jiborn, M. Abrahamson et al., "Cystatin C is downregulated in prostate cancer and modulates invasion of prostate cancer cells via MAPK/Erk and androgen receptor pathways," PLoS ONE, vol. 4, no. 11, Article ID e7953, 2009.

[20] T. Jiborn, M. Abrahamson, V. Gadaleanu, Å. Lundwall, and A. Bjartell, "Aberrant expression of cystatin $\mathrm{C}$ in prostate cancer is associated with neuroendocrine differentiation," $B J U$ International, vol. 98, no. 1, pp. 189-196, 2006.

[21] F. M. Tumminello, C. Flandina, M. Crescimanno, and G. Leto, "Circulating cathepsin $\mathrm{K}$ and cystatin $\mathrm{C}$ in patients with cancer related bone disease: Clinical and therapeutic implications," Biomedicine and Pharmacotherapy, vol. 62, no. 2, pp. 130-135, 2008.

[22] P. Strojan, B. Svetic, L. Šmid, and J. Kos, "Serum cystatin C in patients with head and neck carcinoma," Clinica Chimica Acta, vol. 344, no. 1-2, pp. 155-161, 2004.

[23] E. A. Gashenko, V. A. Lebedeva, I. V. Brak, E. A. Tsykalenko, G. V. Vinokurova, and T. A. Korolenko, "Evaluation of serum procathepsin $\mathrm{B}$, cystatin $\mathrm{B}$ and cystatin $\mathrm{C}$ as possible biomarkers of ovarian cancer," International Journal of Circumpolar Health, vol. 72, no. 1, Article ID 21215, 2013.

[24] J. Kyhse-Andersen, C. Schmidt, G. Nordin et al., "Serum cystatin $\mathrm{C}$, determined by a rapid, automated particle-enhanced turbidimetric method, is a better marker than serum creatinine 
for glomerular filtration rate," Clinical Chemistry, vol. 40, no. 10, pp. 1921-1926, 1994.

[25] C. W. Tsai, M. E. Grams, L. A. Inker, J. Coresh, and E. Selvin, "Cystatin C- and creatinine-based estimated glomerular filtration rate, vascular disease, and mortality in persons with diabetes in the U.S.," Diabetes Care, vol. 37, no. 4, pp. 1002-1008, 2014.

[26] A. Vega, S. García De Vinuesa, M. Goicoechea et al., "Evaluation of methods based on creatinine and cystatin $\mathrm{C}$ to estimate glomerular filtration rate in chronic kidney disease," International Urology and Nephrology, vol. 46, no. 6, pp. 1161-1167, 2014.

[27] T. Salek, P. Vesely, and J. Bernatek, "Estimated glomerular filtration rate in oncology patients before cisplatin chemotherapy," Klinicka Onkologie, vol. 28, no. 4, pp. 273-277, 2015.

[28] M. Zhang, X. Cao, G. Cai et al., "Clinical evaluation of serum cystatin $\mathrm{C}$ and creatinine in patients with chronic kidney disease: A meta-analysis," Journal of International Medical Research, vol. 41, no. 4, pp. 944-955, 2013.

[29] X. Li, H. Zhu, P. Li et al., "Serum cystatin C concentration as an independent marker for hypertensive left ventricular hypertrophy," Journal of Geriatric Cardiology, vol. 10, no. 3, pp. 286-290, 2013.

[30] N. Cimerman, P. M. Brguljan, M. Krašovec, S. Šuškovič, and J. Kos, "Serum cystatin C, a potent inhibitor of cysteine proteinases, is elevated in asthmatic patients," Clinica Chimica Acta, vol. 300, no. 1-2, pp. 83-95, 2000.

[31] J. Helmersson-Karlqvist, M. Flodin, L.-O. Hansson, and A. Larsson, "The age related association is more pronounced for cystatin C estimated GFR than for creatinine estimated GFR in primary care patients," Clinical Biochemistry, vol. 46, no. 16-17, pp. 1761-1763, 2013.

[32] L. D. Colantonio, R. M. Tanner, D. G. Warnock et al., "The role of cystatin- $\mathrm{C}$ in the confirmation of reduced glomerular filtration rate among the oldest old," Archives of Medical Science, vol. 1, pp. 55-67, 2016.

[33] K. Hoang, J. C. Tan, G. Derby et al., "Determinants of glomerular hypofiltration in aging humans," Kidney International, vol. 64, no. 4, pp. 1417-1424, 2003. 


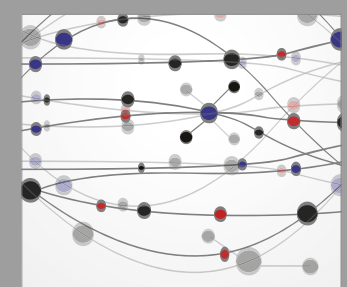

The Scientific World Journal
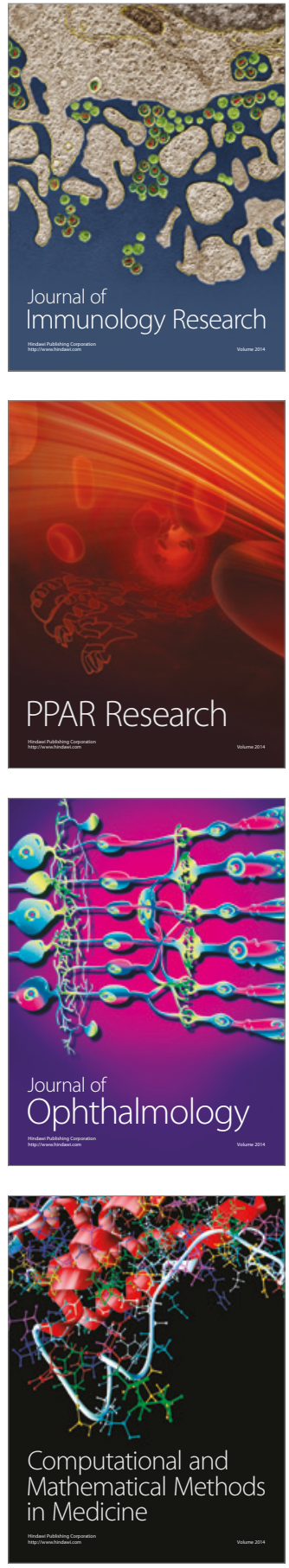

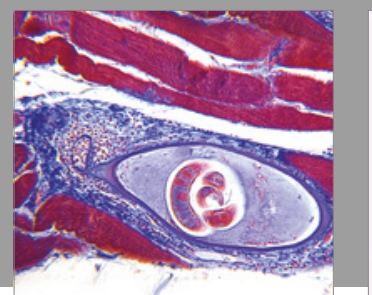

Gastroenterology Research and Practice
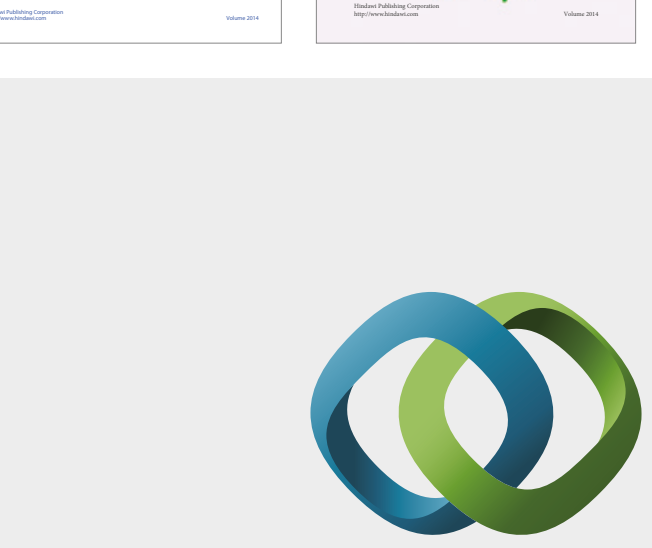

\section{Hindawi}

Submit your manuscripts at

https://www.hindawi.com
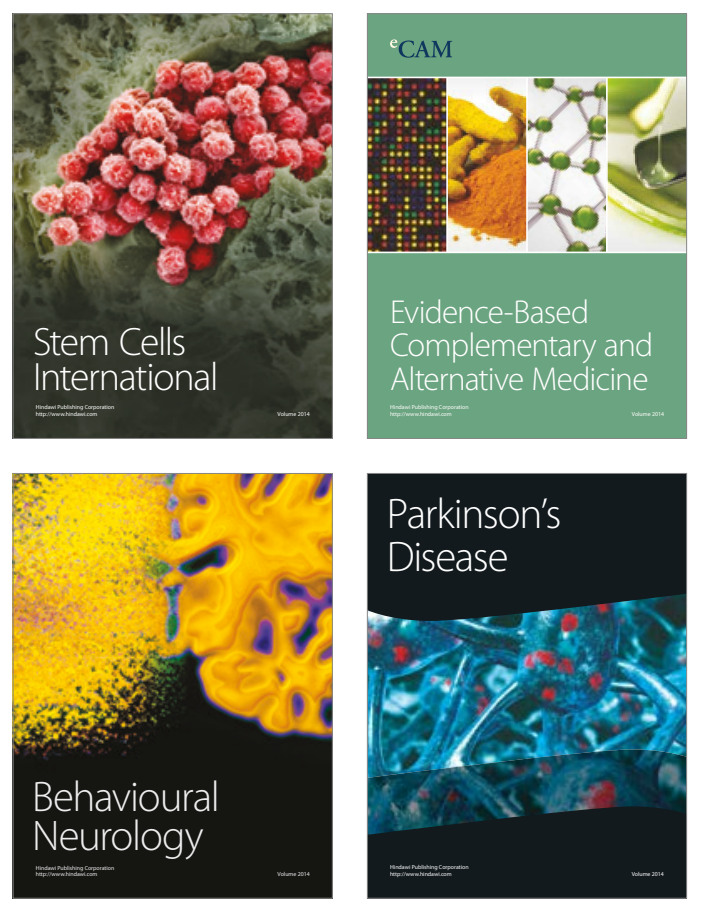
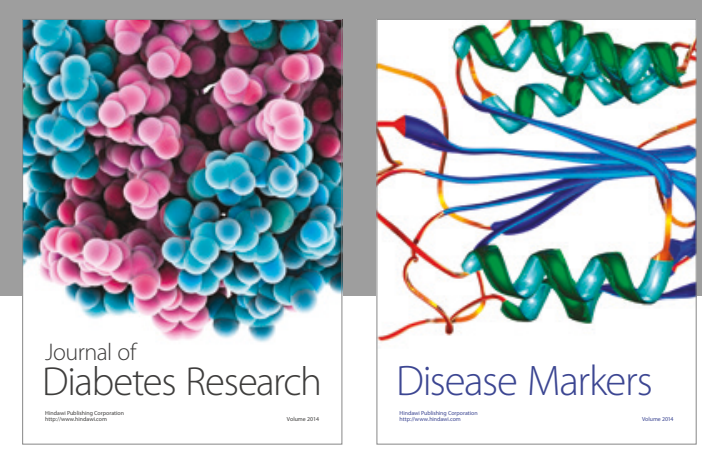

Disease Markers
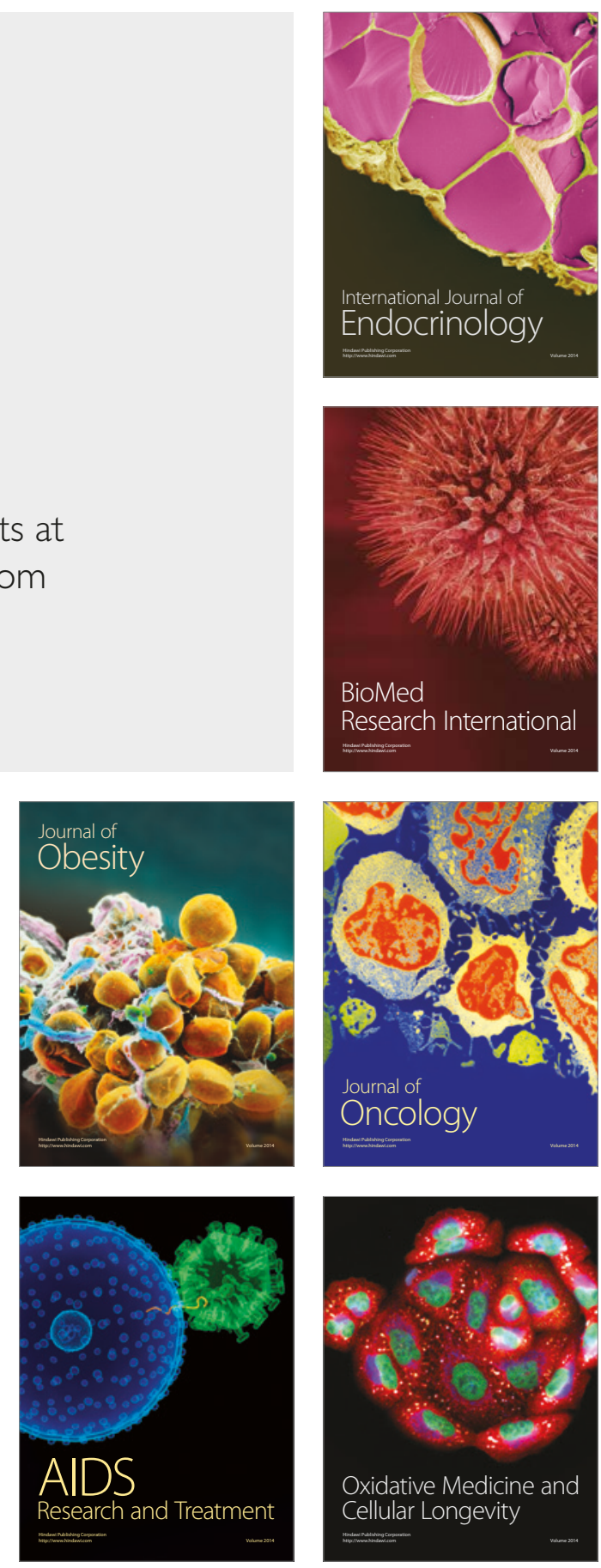